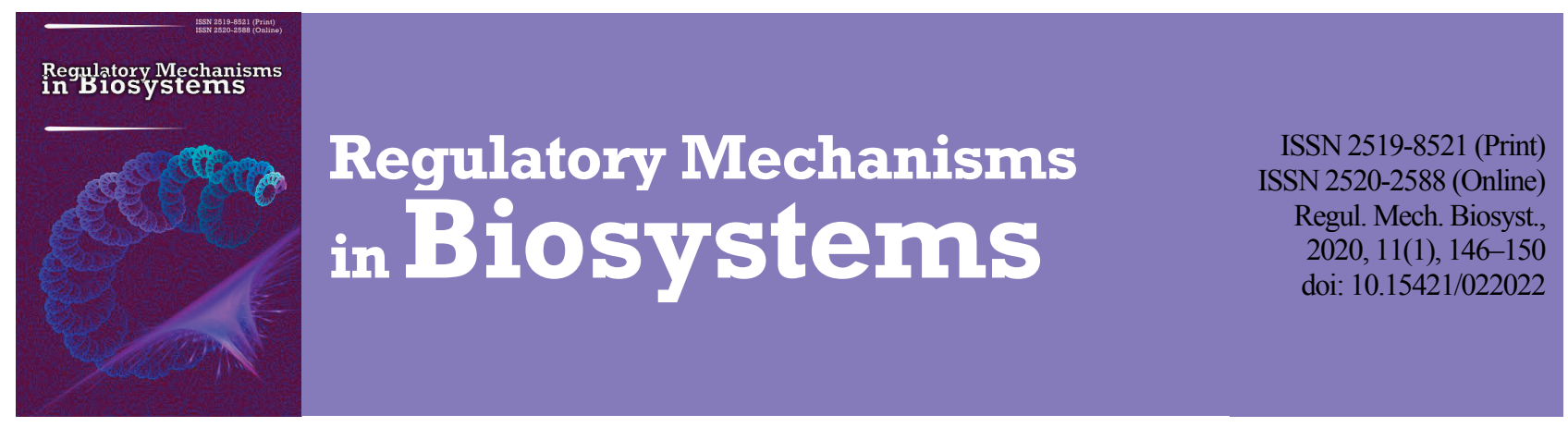

\title{
Influence of toys on behavioural patterns of pigs and their association with the concentration of serotonin in blood plasma
}

\author{
A. V. Lykhach*, V. Y. Lykhach*, M. B. Shpetny**, O. H. Mykhalko**, S. V. Zhyzhka** \\ *National University of Life and Environmental Sciences of Ukraine, Kyiv, Ukraine \\ **Sumy National Agrarian University, Sumy, Ukraine
}

Article info

Received 26.01.2020

Received in revised form 21.02.2020

Accepted 22.02.2020

National University of Life and Environmental Sciences of Ukraine, Heroyiv Oborony st. 15, Kyiv, 03041, Ukraine.

Tel.: +38-068-179-58-57.

E-mail:avlykhach@gmail.com

Sumy National Agrarian University, Gerasim Kondratievst., 160, Sumy, 40000, Ukraine.

Tel.: +38-050-307-20-33.

E-mail:nshpetmy@gmail.com

Lykhach, A. V., Lykhach, V. Y., Shpetny, M. B., Mykhalko, O. H., \& Zhyzhka, S. V. (2020). Influence of toys on behavioural patterns of pigs and their association with the concentration of serotonin in blood plasma. Regulatory Mechanisms in Biosystems, 11(1), 146-150. doi:10.15421/022022

Improvement of welfare of piglets is one of the key factors which underlie the effectiveness of producing pork and the profitability of pig farming. This article offers a solution to the main industrial problem - creation of comfortable maintenance conditions for pigs using toys which satisfy their ethological needs. Piglets used in the experiment were kept in the swine complex of agricultural production of Agrofirm Mig-Service-Agro Cooperative in Novoodesky district of Mykolaiv Oblast (Ukraine). The objective of the study was assessment of the effect of toys on the behaviour of piglets, level of concentration of hormone serotonin in blood plasma and their energy of growth. The experiment was performed on 120 weaned piglets aged 28 days, which were divided according to the principle of analogues with 60 individuals in each group: I - the control group, the animals were kept with no toys; II - the experimental group, where the animals had toys. During the experiment chronometric monitoring of the piglets' behavioural acts was carried out using video observation, we extracted blood samples for determination of the content of the hormone serotonin using the method of highly-efficient fluid chromatography and assessed the growth of the piglets. After the end of the experiment, we determined that the presence of toys reduced the intragroup aggression, which was accompanied by decrease in the duration of fights and almost three-fold increase in playing behaviour. Among piglets which had access to toys, the number of individuals observed to bite tails and ears decreased from 11 to 3 . In the period of the study, the concentration of serotonin in the blood plasma of piglets who had free access to toys was 10 times higher compared with animals of the control group. Change in the behaviour patterns among the animals of the experimental group led to significant differences regarding the parameters of growth, where probable increase in the live weight at the age of 90 days was observed, which was associated with significant increase in their mean daily weight gain compared with the animals of the control group. This study confirms that use of toys for piglets during growth completion can prevent features of aggression and abnormal forms of stereopathy within groups, increase the live weight and mean daily weight gain and improve emotional condition, which affects the welfare of pigs.

Keywords: welfare; emotional condition; stereopathy; intragroup aggression; growth parameters.

\section{Introduction}

Pigs are animals with highly complex behavioural acts and form cooperative social groups. In natural conditions, they spend around half of their time in an environment in which they almost completely realize their search, learning-orientation and explorational behaviours (Stolba \& Wood-Gush, 1984). Usually, for the realization of their natural behaviour they spend up to $40 \%$ of their time in search of tasty food in the soil, especially roots, larvae and even tubers (Horrel et al., 2001; Barnett et al., 2002; Edge et al., 2005).

On the other hand, impossibility of realization of such natural behavioural acts significantly displeases pigs (Blackshaw et al., 1997). In the conditions of modern industrial-based pork production, the technology of growing pigs is usually separated from the natural conditions, causing sensory deprivation and development of stereotypic behaviour among pigs (Apple \& Craig, 1992). The environment of pig-rearing premises is limited, devoid of stimuli to explore and dig, which eventually causes cases of strong aggression, abnormal forms of stereopathy (biting off tails and ears) (Boissy et al., 2007). Thus, pathological intention of some of the animals to dock the tails and ears of the other animals, whereby the traumatized animals lose large amounts of blood, become weak and can even die, which requires the additional expense of veterinary help. Thus, the better the living conditions of piglets, the better is their health (Hongda, 2017).

In order to solve the problem of preventing cases of destabilization of the behaviour in groups of pigs due to aggression, which provokes ethological disorders, they were given constant access to materials which enable pigs' required exploring, digging and search-learning activity, for example straw, hay, wood, sawdust, mushroom compost, peat, algae, scratchers and items which they can bite - plastic "toys", recreational chains, tires, wooden slabs, balls, etc (Grandin et al., 1987; Beattie et al., 2001; Casal-Planaab et al., 2017). Therefore, in Great Britain already in 2003 a law was adopted which envisaged the use of toys to help pigs carry out their natural exploratory behaviour in the form of "manipulative material": balls, footballs, basketball baskets, aromatized wooden balls, etc. (Duncan, 2005; Nowicki \& Kopyra, 2006). In Denmark, the provision of pigs with toy devices started in 2005, when the manufacturers presented Bite-Rite device (Scott et al., 2006). Similar steps are taken in Germany, where it was proposed that pig farmers devote $20 \mathrm{~s}$ of attention a day to each pig for the monitoring of playing behaviour with the help of toys for fulfillment of their behavioural needs. In the United States of America toys for pigs are often used, which imitate the digging behaviour with use of balls for games, rubber toys of Kongs ${ }^{\circledR}$ trademark, puzzles, etc. (Larsen et al., 2016). 
The choice of enriching the environment of pigs should be expedient, and should take into consideration the biological needs of the animals (Grandin \& Curtis, 1984). Toy items must be safe, deformable, and interesting to pigs, should stimulate their playing behaviour (Van de Weerd et al., 2003). Pigs can even lose interest in additional toy items if the abovementioned conditions are ignored (Day et al., 2002).

Unfortunately, in Ukraine and CIS the implementation of such innovative solutions with use of toy objects which would satisfy the behavioural needs of pigs is proceeding quite slowly. And the studies on the influence of toys on the decrease of aggressive behaviour of pigs in the conditions of their industrial breeding are practically absent (Nosov et al., 2005). Usually, playing behaviour of pigs is most often observed among young animals (Bekoff \& Byers, 1998; Brown et al., 2015). Therefore, playing games is a probable criterion of positive emotional state of animals (Mellor et al., 2009; Rius et al., 2018). Along with other functions, games allow animals to develop flexible kinetic and emotionnal reactions to unexpected actions, during which they feel sudden loss of the control (Špinka et al., 2001). Games usually facilitate search-exploring behaviour, contribute to obtaining positive experience or affiliated behaviour in the group (Young \& Moskowitz, 2005; Sommerville et al., 2017).

It is known (Martin \& Bateson, 2007) that emotional state can be evaluated using additional ethological and biochemical methods which can interpret the affective state in the course of playing behavior of animals (Paul et al., 2005; Slivinska et al., 2019). For the assessment of the efficiency of employing toys for to enhance the playing behaviour of pigs, a neuromediator is often used as an indicator of positive state hormone serotonin, because it contributes to good mood, influences the daily rhythms, motor activity, increase in daily weight gain, accompanies discovery activity, influences perception, control of behaviour acts, feeding behaviour, thermal regulation, pain sensitivity, etc (Duncan, 2005; Boissy et al., 2007; Mellor et al., 2009). The role of serotonin in the regulation of behaviour is known to be complex, including regulation of mood and emotional state, contributes to calm and stabilizes intragroup hierarchy (Landsberg et al., 2013). Ursinus et al. (2013) revealed that serotonin affected the behaviour of pigs during the novelty test, and also their searching-exploring and orientation activity. At low concentration of serotonin in blood plasma in animals, aggressive behaviour, disorders, frustration, boredom were observed, therefore reducing the productivity of quality of pigs (Insel \& Winslow, 1998; Young \& Moskowitz, 2005). Therefore, of great value for the welfare of pigs is the access of pigs to toys, which increases their motor, searching, exploratory and discovery activities, and therefore increases the level of serotonin hormone, indicating the positive emotional state of the animals. The effect of toys on the behaviour of piglets, level of the concentration of serotonin hormone in blood plasma and their growth intensity were the objectives of our study.

\section{Materials and methods}

Rules of maintaining the animals in the experiment were observed completely: the animals were provided with comfortable conditions of feeding, watering, maintenance, care, prophylaxis and treatment, with accordance with the European Legislation on the Protection of Animals and their Comfort of Farm Animals (Council Directive No 95/58 of the EU concerning the protection of animals kept for farming purposes of the European Parliament from 20 July 1998 with amendments made by the Regulation of the EU No 806/203 from 14 April 2003, No 91/630 "Minimum standards for the protection of pigs" from 19 November 1991 with amendments made by the Regulations of the EU). The protocol of the experimental study on blood withdrawal from piglets, was approved by the local Commission on Bioethics of the National University of Life and Environmental Sciences of Ukraine regarding the General Clinical Practice (GCP) on the Protection and Humane Attitude of the Experimenters to the Experimental Animals.

The research on the influence of toys on the behaviour of piglets and their growth were conducted on animals, where the mother form was a crossbreed of white large breed and Landras breed, and father form - Maxgroo terminal boar, which were kept in the swine complex of the Agricultural Production Cooperative Agrofirm Mig Service Agro (Novoodesky district, Mykolaiv Oblast, Ukraine).

All the experimental animals were divided into two groups (according to the principle of analogues) with 60 individuals in each: I - the control group, the animals of which were kept with no toys; II - the experimental group with animals access to toys. The age of piglets at the beginning of the experiment was 28 days. The feeding of piglets of both experimental groups was identical according to the detailed norms of feeding, taking into consideration the physiological peculiarities of the animals.

Toys in the conditions of the enterprise were the elements of ropewasher constructions hanging on chains (Fig. 1). During the experiment, we timed the behaviour acts of the piglets of both groups using video observation with Full HD 1080p video recorders (with maximum resolution of 1920 x 1080, $30 \mathrm{fps}$ ) with AVI the recording format.

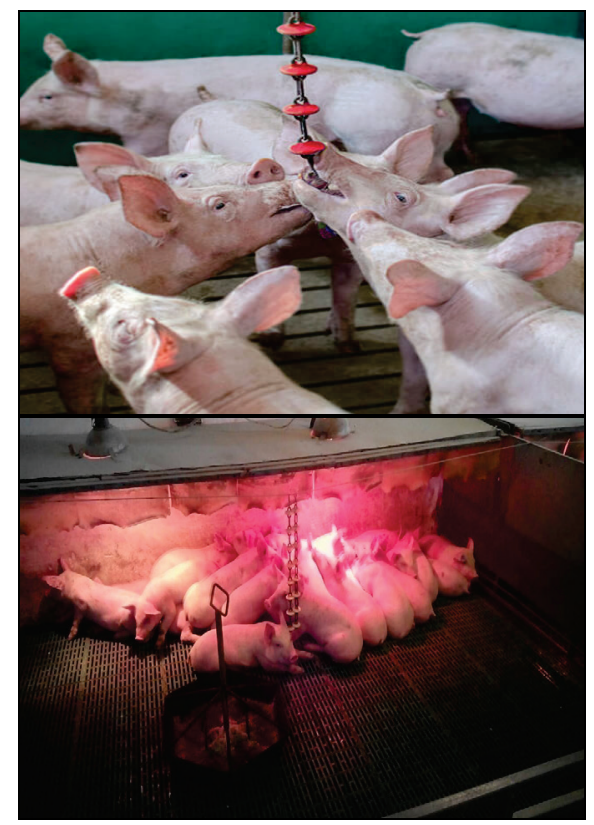

Fig. 1. General view of the toys used for the piglets over the experiment

Visual observations on the animals were made from 7 AM to $7 \mathrm{AM}$ of the following day with determination of duration (in minutes) of behavioural acts - rest, consumption of feed and water, movement, fights and games. Observations on the behaviour of the piglets and withdrawal of blood followed by laboratory assay for the content of serotonin hormone were performed 5, 35 and 65 days after the beginning of the experiment. For this purpose, from 10 individuals of the piglets of the control and experimental groups (on an empty stomach) blood was withdrawn from the ear vein in the amount of $10 \mathrm{~mL}$.

Analysis of the blood samples was performed in the clinical laboratory of the Ukrainian Medical-Diagnostic center (Kyiv) on the basis of HPLC method (highly efficient fluid chromatography, analyzer and the test system) with Agilent 1100 chromatograph (Agilent Technologies Recipe, USA).

This method is based on the formation of fluorescent complex during condensation of serotonin with ninhydrin, and the level of fluorescence of the solution over the employment of this method is proportional to the serotonin concentration. In order to determine serotonin to $1 \mathrm{~mL}$ of the acidic phase, we added $1 \mathrm{~mL}$ of phosphate buffer with $8.0 \mathrm{pH}$ (at the same time the $\mathrm{pH}$ level in the solution reduced to 7.0) and $0.2 \mathrm{~mL}$ of $0.1 \mathrm{M}$ pf ninhydrin solution. The mixture was incubated for $30 \mathrm{~min}$ at the temperature of $75^{\circ} \mathrm{C}$, and then kept for one hour at room temperature, the volume made up to equal $5 \mathrm{~mL}$ and the fluorescence was measured in the range of $490 \mathrm{~nm}$ in the light with wavelength equaling 360-365 nm.

For the calibration, samples containing $0.05 \mu \mathrm{g}$ of serotonin were taken, their volume was adjusted to $1.5 \mathrm{~mL}$ using distilled water and $0.5 \mathrm{~mL}$ of $1 \mathrm{~N}$ perchloric acid was added. Calibration and perchloric samples were extracted using butanol-chloroform mixture after addition 
of $0.2 \mathrm{~mL}$ of $5 \mathrm{~N}$ of $\mathrm{NaOH}$ and processed in the same manner as the experimental sample. The level of fluorescence of the perchloric sample was calculated on the basis of the results obtained for the experimental and calibration samples (Karpyshchenko, 2012).

At the age of 90 days, live weight $(\mathrm{kg})$ of pigs was determined in both groups, and also their mean daily increment (g) during the period of the experiment.

The results are presented as mean \pm standard deviation $(\mathrm{x} \pm \mathrm{SD})$. The data were analyzed using Statistica 12.0 program (StatSoft Inc., 2014, www.statsoft.com). Values of differences between the features $(\mathrm{P}<0.05)$ were determined using dispersion analysis (ANOVA). In the study the following system of probability was employed: $\mathrm{P}<0.05,0.01$ and 0.001 .

\section{Results}

Change in the main behavioural acts of piglets of the control and experimental groups was observed already on the 5 th day of the experiment (Table 1). The animals which had access to the toys were characterized by longer rest compared with the piglets of the control group, lower aggression accompanied by lower number of fights, and, as expected, an almost three-fold increase in the duration of playing behaviour.

\section{Table 1}

Influence of toys on the duration of the behaviour acts of piglets depending on the day of the experiment ( $\min , \mathrm{x} \pm \mathrm{Sd}, \mathrm{n}=60)$

\begin{tabular}{|c|c|c|}
\hline Behaviour act & Control group & Experimental group \\
\hline \multicolumn{3}{|c|}{5 days of the experiment } \\
\hline Rest & $786.3 \pm 23.9$ & $879.2 \pm 22.8^{* *}$ \\
\hline Consumption of feed and water & $145.7 \pm 4.8$ & $150.5 \pm 5.1$ \\
\hline Moving & $435.2 \pm 14.5$ & $400.4 \pm 15.1$ \\
\hline Fights & $32.8 \pm 5.1$ & $15.2 \pm 3.8^{* *}$ \\
\hline Games & $11.9 \pm 3.8$ & $38.8 \pm 12.8^{*}$ \\
\hline \multicolumn{3}{|c|}{35 days of the experiment } \\
\hline Rest & $900.8 \pm 30.3$ & $932.7 \pm 34.1$ \\
\hline Consumption of feed and water & $140.1 \pm 5.1$ & $133.2 \pm 4.7$ \\
\hline Moving & $406.8 \pm 14.8$ & $311.5 \pm 13.8^{* * *}$ \\
\hline Fights & $15.6 \pm 3.4$ & $3.4 \pm 1.7^{* * *}$ \\
\hline Games & $14.1 \pm 4.2$ & $35.5 \pm 11.2$ \\
\hline \multicolumn{3}{|c|}{65 days of the experiment } \\
\hline Rest & $842.4 \pm 27.1$ & $872.5 \pm 25.5$ \\
\hline Consumption of feed and water & $142.8 \pm 4.8$ & $138.5 \pm 4.2$ \\
\hline Moving & $386.9 \pm 13.9$ & $356.8 \pm 14.2$ \\
\hline Fights & $12.3 \pm 4.2$ & $2.5 \pm 1.2^{*}$ \\
\hline Games & $14.9 \pm 5.1$ & $37.8 \pm 16.2$ \\
\hline
\end{tabular}

Note: ${ }^{*}-\mathrm{P}<0.05,{ }^{* *}-\mathrm{P}<0.01,{ }^{* * *}-\mathrm{P}<0.001$.

On the 35th day of the experiment the piglets that had access to toys exhibited lower activity in moving behaviour, including an almost fivefold decrease in the cases of aggression between individuals and inside the group $(\mathrm{P}<0.001)$.

On the 65th day of the experiment, between the animals of the different groups, we observed only differences regarding the duration of fights $(\mathrm{P}<0.05)$, whereas for the rest of the main behaviour acts, no probable differences between the animals with access to toys and animals of the control were observed. Despite recording higher activity in playing behaviour among piglets of the experimental group on the 35th and 65th days of the experiment, no probable difference compared to the animals of the control group was seen. However, this can be attributed to significant individual differences among the piglets of the experimental group regarding their reaction to the presence of toys, manifested in the increase in statistical error of mean duration of this type of behavior of animals of the experimental group.

An important manifestation of the decrease in the aggressive behavior among the animals that had free access to toys is a significant decrease in the number of cases of tail- and ear-docking. If the animals of the control group throughout the experiment were observed to have 11 cases of biting, among the piglets which were able to transfer their aggression onto toys, only three such cases were observed. The animals of the control and experimental groups were characterized by significant differences in the concentration of serotonin in blood plasma (Table 1). On the 5th day of the experiment serotonin in blood plasma of the animals of both groups was somewhat lower than the norm of the biological reference interval, which is related to stress after weaning of the piglets from sows, and as a result their aggressive behaviour.

\section{Table 2}

Influence of toys on the concentration of serotonin in blood plasma of piglets depending on the day of the experiment $(\mu \mathrm{mol} / \mathrm{L}, \mathrm{x} \pm \mathrm{SD}, \mathrm{n}=10)$

\begin{tabular}{lcc}
\hline Duration of the experiment, days & Control group & Experimental group \\
\hline 5 & $0.16 \pm 0.003$ & $0.15 \pm 0.003$ \\
35 & $0.18 \pm 0.004$ & $2.15 \pm 0.071^{* * *}$ \\
65 & $0.21 \pm 0.005$ & $2.77 \pm 0.096^{* * *}$ \\
\hline
\end{tabular}

Notes: biological reference interval $0.22-2.05$; *** $-\mathrm{P}<0.001$.

Both on the 35th and 65th days of the experiment the concentration of serotonin in the blood of piglets which had free access to toys was almost ten times higher than in the animals of the control group (in both cases: $\mathrm{P}<0.001$ ), and the piglets of the control were observed to have continuous anxiety caused by increased locomotion activity (Table 1 ).

Such distribution of serotonin hormone in the control and experimental groups indicate that the piglets with no toys in the pens showed clearly expressed aggressive behavior, disorders, apathy, frustration, boredom, which significantly destabilized the animals' behaviour and induced fights between piglets and discomfort, or even manifestation of abnormal forms of stereopathy (biting tails, ears, etc.), which in turn significantly decreases the productivity of young pigs and welfare of piglets during growth completion.

In general the change in behavioural patterns among the animals of the control and experimental groups caused significant differences in the parameters of their growth and development (Table 3).

Table 3

Influence of toys on the growth parameters of piglets from mating of $+(\mathrm{WLB} \times \mathrm{LB}) \times \overbrace{}^{\lambda}$ Maxgroo in the conditions of the experiment $(x \pm S D, n=60)$

\begin{tabular}{lrc}
\hline \multirow{2}{*}{ Parameter } & \multicolumn{2}{c}{ Group } \\
\cline { 2 - 3 } & \multicolumn{1}{c}{ control } & experimental \\
\hline Live weight of piglets at the moment & $10.6 \pm 0.32$ & $10.7 \pm 0.28$ \\
of subjection to growth completion, $\mathrm{kg}$ & $36.8 \pm 0.41$ & $38.4 \pm 0.52^{*}$ \\
Live weight of piglets at the age of 90 days, $\mathrm{kg}$ & $476.4 \pm 5.61$ & $503.6 \pm 4.42^{* * *}$ \\
\hline
\end{tabular}

Note: ${ }^{*}-\mathrm{P}<0.05, * * *-\mathrm{P}<0.001$.

Among the piglets which had free access to toys, probable increase in live weight at the age of 90 days $(\mathrm{P}<0.05)$ was observed, related to significant increase in their average daily weight gain compared with animals of the control group ( $\mathrm{P}<0.001)$. Therefore, piglets on growth completion kept in boxes with toys, were less anxious and active, which affected the intensity of their growth parameters.

\section{Discussion}

The process of mixing piglets of different nests during the period of growth completion, generally is a consequence of stressed state of the animals, which induced their aggressiveness (D'Eath, 2002). Usually significant aggressive relations between the pigs are recorded in the first hours after re-grouping (Arey \& Franklin, 1995). The conducted experiment brightly demonstrates the fact that after formation of the groups of piglets, from the beginning of the experiment, their locomotion activity regardless of the purpose of the groups was $50 \%$ higher, which is explained by establishment of social hierarchy and division between the piglets of desired places in the boxes.

In our experiment, absence of "enriching objects" affected the behaviour of weaned piglets. The results of the obtained studies (Pearce \& Paterson, 1993) confirmed that such toy constructions as chains, car tires significantly intensify the exploration behaviour of pigs, though they have no effect on the duration of activity. Our studies confirm the published results, because the interest of young pigs in the experiment was high in the days following its start. 
The presence of movable toys influenced the behaviour of pigs and decreased their aggressiveness, correspondingly contributing to reducing their traumatism (Grandin \& Curtis, 1984). The periods of rest in the animals of the control group of animals were anxious, often interrupted when the pigs got up and moved, and the number of fights in the control group accounted for 60.7, whereas among the experimental group of piglets the number of fights was three times lower, and for one collision the piglets of both groups spent approximately the same amount of time. Use of toys in the experimental group contributed to diversion of piglets by other objects, therefore creating ethologically comfortable conditions for weaning the piglets, which resulted in decrease of aggression (40.6\% fewer fights than in the control group) with fewer cases of biting ears and tails. Similar results on the low number of bitten ears and tails in the environment crowded with toy devices were obtained by other researchers (Van de Weerd et al., 2006).

The animals of the experimental group spent oup to $2.0-20.7 \%$ of $24 \mathrm{~h}$ playing. This fact indicates that social hierarchy was established quicker in the groups with toys, which improved their adaptation to the new environment. These observations are consistent with the conclusions (Blackshaw et al., 1997) which suggest that the influence of toys reduces the level of aggression. A number of data confirm that additional "enriching" objects decrease "social pressure" by re-distribution of the aggression (Newberry, 1995; Keeling \& Gonyou, 2001).

By the concentration of serotonin in blood plasma, it was determined that the animals which had access to toys exhibited continuous anxiety and locomotion activity increased by $23.4 \%$ compared with the analogues of piglets of the control group. Moreover, deficiency of serotonin hormone in piglets of the control group manifested in decrease in their exploratory behaviour which was reflected in certain orientation and tactile-moving reactions of the behaviour of young pigs (sniffing, examination, attentively listening, moving in the pens, defecation).

Distribution of serotonin in piglets of the control and experimental groups indicates that piglets which had no toys in the pens were observed to exhibit clearly aggressive behaviour, disorders, apathy, frustration, boredom, which significantly destabilizes the behaviour of animals, causing induction of fights between piglets and discomfort or manifestation of abnormal forms of stereopathy (biting the tails, ears), which in turn significantly reduces the growth parameters of young pigs. The obtained results correlate with those of researchers who studied the behaviour of pigs by providing them with "enriching" items with subsequent determination of their emotional state by measuring the concentration of serotonin hormone in their blood (Ursinus et al., 2013).

\section{Conclusions}

We assessed the effect of toys on the behaviour of piglets, level of the serotonin hormone concentration in blood plasma and the piglets' intensity of growth. The proposed toy construction for the piglets in boxes for growth completion influenced their behavioural patterns, where the animals of the experimental group spent more time on rest, consumption of feed and water and moved less compared with the control animals. Due to the toys, fewer fights occurred between the piglets, increase was observed in the orientation-searching, exploration activities and playing, with no signs of aggression, or of abnormal forms of stereopathy and traumatism, which was indicated in the animals' calm emotional state, significantly higher concentration of serotonin hormone in blood plasma and increase in the growth parameters of pigs. Therefore, use of toys contributes to both rapid establishment of social hierarchy and adaptation of piglets to the maintenance conditions, and improvement of the effectiveness of pig farming.

\section{References}

Apple, J. K., \& Craig, J. V. (1992). The influence of pen size on toy preference of growing pigs. Applied Animal Behavior Science, 35(2), 149-155.

Arey, D. S., \& Franklin, M. F. (1995). Effects of straw and unfamiliarity on fighting between newly mixed growing pigs. Applied Animal Behavior Science, 45, 23-30.

Beattie, V. E., Sneddon, I. A., Walker, N., \& Weatherup, R. N. (2001). Environmental enrichment of intensive pig housing using spent mushroom compost. Animal Science, 72, 35-42.
Bekoff, M., \& Byers, J. A. (1998). Animal play: Evolutionary, comparative and ecological perspectives. Cambridge University Press, Cambridge.

Blackshaw, J. K., Thomas, F. J., \& Lee, J.-A. (1997). The effect of a fixed or free toy on the growth rate and aggressive behavior of weaned pigs and the influence of hierarchy on initial investigation of the toys. Applied Animal Behavior Science, 53(3), 203-212.

Boissy, A., Manteuffel, G., Jensen, M. B., Moe, R. O., Spruijt, B., Keeling, L. J., Winckler, C., Forkman, B., Dimitrov, I., Langbein, J., Bakken, M., Veissier, I., \& Aubert, A. (2007). Assessment of positive emotions in animals to improve their welfare. Physiology and Behavior, 92, 375-397.

Brown, S. M., Klaffenböck, M., Nevison, I. M., \& Lawrence, A. B. (2015). Evidence for litter differences in play behavior in pre-weaned pigs. Applied Animal Behavior Science, 172, 17-25.

Barnett, H. L. I., Edge, H. L., \& Edwards, S. A. (2003). Alternatives to nose ringing in outdoor sows: 1 . The provision of a sacrificial rooting area. Applied Animal Behavior Science, 83(4), 267-276.

Casal-Planaab, N., Mantecab, X., Dalmaua, A., \& Fàbregaa, E. (2017). Influence of enrichment material and herbal compounds in the behavior and performance of growing pigs. Applied Animal Behavior Science, 195, 38-43.

D'Eath, R. B. (2002). Individual aggressiveness measured in a resident-intruder test predicts the persistence of aggressive behavior and weight gain of young pigs after mixing. Applied Animal Behavior Science, 77, 267-283.

Day, J. E. L., Spoolder, H. A. M., Burfoot, A., Chamberlain, H. L., \& Edwards, S. A. (2002). The separate and interactive effects of handling and environmental enrichment on the behavior and welfare of growing pigs. Applied Animal Behavior Science, 75, 177-192.

Duncan, I. J. (2005). Science-based assessment of animal welfare: Farm animals. Revue Scientifique et Technique - Office International des Epizooties, 24(2), 483-492.

Edge, H. L., Bulman, C. A., \& Edwards, S. A. (2005). Alternatives to nose ringing in outdoor sows: The provision of root crops. Applied Animal Behavior Science, 92(1), 15-26.

Fraser, D. (1984). The role of behavior in swine production: a review of research. Applied Animal Ethology, 11,317-339.

Grandin, T., \& Curtis, S. E. (1984). Toy preferences in young pigs. Animal Science, $59,85$.

Grandin, T., Curtis, S. E., \& Taylor, I. A. (1987). Toys, mingling and driving reduce excitability in pigs. Journal Animal Science, $65,230$.

Horrell, I., Ness, P. A., Edwards, S. A., \& Eddison, J. (2001). The use of nose ringing in pigs: consequences for rooting, other functional activities and welfare. Animal Welfare 10,3-22.

Insel, T. R., \& Winslow, J. T. (1998). Serotonin and neuropeptides in affiliative behaviors. Biology Psychiatry, 44, 207-219.

Karpyshchenko, A. Y. (2012). Medytsynskye laboratornie tekhnolohyy (rukovodstvo po klynycheskoi laboratornoi dyahnostyke) [Medical laboratory technology (Clinical laboratory diagnostics guide)]. Novosti, Moscow (in Russian).

Keeling, L. J., \& Gonyou, H. W. (2001). Social behavior in farm animals. CAB International.

Landsberg, G., Hunthaussen, W., \& Ackerman, L. (2013). Behavior problems of the dog and cat. Third edition. Saunders Ltd, Philadelphia.

Larsen, M. L. V., Andersen, H. M., \& Pedersen, L. J. (2016). Can tail damage outbreaks in the pig be predicted by behavioral change? The Veterinary Journal, 209, 50-56.

Martin, P., \& Bateson, P. (2007). Measuring behavior, an introductory guide. Third edition. Cambridge University Press, Cambridge.

Mellor, D., Patterson-Kane, E., \& Stafford, K. J. (2009). The sciences of animal welfare (UFAW animal welfare). John Wiley \& Sons, Palmerston North.

Newberry, R. C. (1995). Environmental enrichment: Increasing the biological relevance of captive environments. Applied Animal Behavior Science, 44, 229-243.

Nosov, A. N., Zhuchaev, K. V., \& Papshev, S. V. (2005). Vliyanie "obogashheniya sredy" pri peregruppirovke na povedenie molodnyaka svinej [The effect of enriched medium during regrouping on the behavior of young pigs]. Vestnik Novosibirskogo Gosudarstvennogo Agrarnogo Universiteta, 2, 69-74 (in Russian).

Nowicki, J., \& Kopyra, M. (2006). Preliminary investigations of the influence of free wooden ball in pen on the behavior and growth rate of newly mixed weaners. Annals of Animal Science, 2(1), 95-100.

Paul, E. S., Harding, E. J., \& Mendl, M. (2005). Measuring emotional processes in animals: The utility of a cognitive approach. Neuroscience Biobehavioral Reviews, 29, 469-491.

Pearce, G. P., \& Paterson, A. M. (1993). The effect of space restriction and provision of toys during rearing on the behavior, productivity and physiology of male pigs. Applied Animal Behavior Science, 36, 11-28.

Rius, M. M., Cozzi, A., Bienboire-Frosini, C., Teruel, E., Chabaud, C., Monneret, P., Leclercq, J., Lafont-Lecuelle, C., \& Pageat, P. (2018). Selection of putative indicators of positive emotions trigegered by object and social play in mini pigs. Applied Animal Behavior Science, 202, 13-19. 
Scott, K., Taylor, L., Gill, B. P., \& Edwards, S. A. (2006). Influence of different types environmental enrichment on the behavior of finishing pigs in two different housing systems. 1. Hanging toy versus root able substrate. Applied Animal Behavior Science, 99, 222-229.

Slivinska, L. G., Shcherbatyy, A. R., Lukashchuk, B. O., Zinko, H. O., Gutyj, B. V., Lychuk, M. G., Chernushkin, B. O., Leno, M. I., Prystupa, O. I. Leskiv, K. Y., Slepokura, O. I., Sobolev, O. I., Shkromada, O. I., Kysterna, O. S., \& Musiienko, O. V. (2019). Correction of indicators of erythrocytopoesis and microelement blood levels in cows under conditions of technogenic pollution. Ukrainian Journal of Ecology, 9(2), 127-135.

Sommerville, R., O'Connor, E. A., \& Asher, L. (2017). Why do dogs play? Function and welfare implications of play in the domestic dog. Applied Animal Behavior Science, 197, 1-8.

Špinka, M., Newberry, R. C., \& Bekoff, M. (2001). Mammalian play: Training for the unexpected. Quarterly Review of Biology, 76, 141-168.

Stolba, A., \& Wood-Gush, D. G. M. (1984). The identification of behavioral key features and their incorporation into a housing design for pigs. Annals of Veterinary Recearch, 15, 287-298.
Studnitz, M., Jensen, K. H., \& Jorgensen, E. (2003). The effect of nose ringing on the exploratory behavior of outdoor gilts exposed to different tests. Applied Animal Behavior Science, 84(1), 41-57.

Ursinus, W. W., Bolhuis, J. E., Zonderland, J. J., Rodenburg, T. B., de Souza, A. S., Koopmanschap, R. E., Kemp, B., Korte-Bouws, G. H., Korte, S. M., \& van Reenen, C. G. (2013). Relations between peripheral and brain serotonin measures and behavioral responses in a novelty test in pigs. Physiology and Behavior, 118, 88-96.

Van de Weerd, H. A., Docking, C. M., Day, J. E. L., Avery, P. J., \& Edwards, S. A. (2003). A systematic approach towards developing environmental enrichment for pigs. Applied Animal Behavior Science, 84, 101-118.

Van de Weerd, H. A., Docking, C. M., Day, J. E. L., Breuer, K., \& Edwards, S. A. (2006). Effects of species-relevant environmental enrichment on the behavior and productivity of finishing pigs. Applied Animal Behavior Science, 99, $230-247$.

Young, S. N., \& Moskowitz, D. S. (2005). Serotonin and affiliative behavior. Behavior Brain Science, 28, 367-368. 